Health Care Delivery in Anaesthesia. RA Hirsh, WH Forrest, FK Orkia, H Woolman (Eds), George F. Stickley Co. Philadelphia 1980: 105-18.

3 Gibbs, CP. Krischer J, Peckham BM. Sharp H, Kirschbaum TH. Obsteric anesthesia: a national survey. Anesthesiology 1985: 65: 298-306.

4 The Canadian Medical Association. Ottawa, Ontario. Obstetrics 87: A Report on Obstetrical Care in Canada. March: 1987.

\section{Selection and training of anaesthetic residents}

Is the study of the selection and training/assessment of anaesthetic residents important? After all, as the specialty has developed, recruitment has been on the basis of accepting anaesthetic residents in a rather informal, unstructured way. This may be either by personal referral, "Plays a great game of golf," or by interview, by anaesthetists who lack formal training in interview techniques for candidate selection. This process seems to be working, as the risk of death from anaesthesia has decreased over the years from about $1 / 2500$ to $1 / 10,000$. $^{\prime}$

However, this may be an erroneous assumption, as the major improvement in anaesthetic mortality is probably due to a decrease in the number of deaths related to equipment and drug problems. In comparison to the American airline industry, for which there are about 125 deaths $/ 200$ billion passenger miles, anaesthesia-related deaths figure at $1-3 / 10,000$ anaesthetics. ${ }^{2}$ The continued escalation of costs for malpractice insurance (in Canada from $\$ 500$ in 1983 to $\$ 8250$ in 1987) is a further reminder that mishaps do occur. Unfortunately, the major cause of anaesthesia-attributable deaths is human ertor or anaesthetist failure: lack of care, knowledge, experience accounting for about 80 per cent of mishaps.

Thus, because the major source of problems is usually the anaesthetist, and in order to ensure the continued and future excellence of the specialty, there is a need to examine who will practice anaesthesia in the future, i.e., to examine how we select, train and assess anaesthetists. A compounding problem is that there are no criteria, either for selection (who?) or for training/assessment (how?). For example, it may be possible to train anyone! The measures of success are in day-to-day performance, on which personality variables have an effect, and in long-term ability, most affected by motivational factors.

\section{Selection}

In 1980, Reeve published a study entitled "Personality characteristics of a sample of anaesthetists. ${ }^{n 3}$ He examined 231 anaesthetists (171 male, 60 female) with Cattell's 16 Personality Factors Questionnaire, demographics and leisure interests, likes/dislikes/job satisfaction, and "performance critera." He found anaesthetists to be "reserved, intelligent, assertive, serious, conscientious, self-sufficient, tense, less socially bold, and selfassured," in comparison to either the general population or general practitioners. He went on to decry current selection techniques, on the basis of the "alarmingly high lcvel of wastage" in anaesthetists, as well as the "major role of human error in mortality data." He suggested that there was probably an "unsuitable personality," but did not define what the suitable personality for the job was, nor what the job itself was.

\section{Training/assessment}

To add to the problem of selection, there is no definition of what the final product of anaesthetic training should be. Furthermore, the specialty is changing, thus compounding the task of setting criteria. Anaesthesia has developed from a specialty of "low tech/high touch"4 (hands on the patient, minimal monitoring equipment) to "high tech/ low touch"4 (often unable to approach the patient easily because of the multitude of monitors).

Anaesthetic training should be designed to outlast the residency period. For example, a major part of the time spent in the practice of anaesthesia is devoted to the maintenance of vigilance, a series of diverse tasks requiring "both visual attention and manual dexterity," and an "endeavour largely dependent on training." Lack of vigilance during routine procedures has been described as a case of "familiarity breeds contempt." Training should prevent this, but selection of an unsuitable candidate may outweigh efforts at education. The end of the residency is the start of the process of "aging" of the anaesthetist. Skills increase with experience, but knowledge declines. A third factor, diligence, must be present in those selected, honed during training, and not dulled from the boredom of repetition that constant work may engender. As Cooper stated, "perhaps the most insidious hazard of anesthesia is its relative safety."7 There is the additional danger of "getonwithititis," as the risk of eutting comers is seemingly small, ${ }^{7}$ whether it be in the preoperative, preinduction, or postinduction periods.

How best then to select'train/evaluate anaesthetic residents? In order to answer this, in 1986 a pilot study of anaesthetic residents at six Canadian training centres was undertaken. Residents were examined with respect to demographics, attitudes to anaesthesia, and self- 
evaluation (by means of the dimensions found in Cattell's 16 Personality Factors questionnaire). This study showed the possibility of examining all sixteen programs in Canada, and this began in July, 1987. All beginning residents were enrolled voluntarily in a confidential, four-year, longitudinal study. Tests used are the same as for the pilot study, with the addition of the Adjective Check List. Program directors and characteristics of the programs will also be examined. The results of this study should give some indication of the future of anaesthesia in Canada.

\section{References}

1 Davies JM, Strunin L. Anaesthesia in 1984: how safe is it? Can Med Assoc J 1984; 131: 437-41.

2 Gravenstein JS, Weinger $M B$. Editorial. Why investigate vigilance? J Clin Monitoring 1986; 2 : 145-7.

3 Reeve PE. Personality characteristics of a sample of anaesthetists. Anaesthesia 1980; 35: 559-68.

4 Naisbitt J. Megatrends. Wamer Books Edition, New York, 1982.

5 Green RA, Taylor $T H$. An analysis of anesthesia medical liability claims in the United Kingdom, 1977-1982. Intemational Anesthesiology Clinies 1984; 22 : 73-89.

6 Cooper $J B$, Newbower RS, Kitz RJ. An analysis of major errors and equipment failures in anesthesia management: considerations for prevention and detection. Anesthesiology 1984; 60: 34-42.

7 Gaba DM, Maxwell M, DeAnda A. Anesthetic mishaps: breaking the chain of accident evolution. Anesthesiology 1987 ; 65: 670-6. 